\title{
Incapacidade, cotidiano e subjetividade: a narrativa de trabalhadores com LER/DORT
}

Robson da Fonseca Neves ${ }^{1}$

Mônica de Oliveira Nunes²

NEVES, R.F.; NUNES, M.O. Disability, everyday life and subjectivity: the narrative of workers with RSI/WMSD. Interface - Comunic., Saude, Educ., v.13, n.30, p.55-66, jul./ set. 2009.

The aim was to examine how workers with repetitive strain injuries (RSIs)/ work-related musculoskeletal disorders (WMSDs) experience sickness, by drawing upon the notions of "experience of illness" and "disease narratives". The narrative interview technique and thematic analysis were used to understand the categories emerging from the discourse of the eight participants in this study. The results indicated that "body inefficiency" for work was shown by the mismatch between the production required for the work and what the workers' bodies produced. The body played a sign-supporting role regarding changes in behavior and body structure, thereby helping to consolidate the imagery of disability. Thus, metaphors publicly attested to professional decline and discredited the condition of illness. It was concluded that although the disability was expressed early among the perceptions of the workers' inefficiency within the productive process, it seemed to be legitimated later, at the cost of the workers' chronic disease and disability.

Keywords: Illness experience. Disability. RSI/WMSD. Occupational diseases.
Objetivou-se conhecer a experiência de adoecimento de trabalhadores com Ler/ Dort, apoiando-se nos pressupostos da "experiência de enfermidade" e nas "narrativas da doença". Foram utilizadas a técnica de entrevista narrativa e a análise temática para se apreenderem as categorias que emergiram do discurso dos oito sujeitos participantes desta pesquisa. Os resultados apontam que a "ineficiência do corpo" para o trabalho foi evidenciada pelo descompasso entre a produção exigida pelo trabalho e a produzida pelo corpo do trabalhador. O corpo funciona como um "suporte de signos" das mudanças no comportamento e nas estruturas do corpo, ajudando a consolidar o imaginário de incapacidade. "As metáforas" representam o atestado público de declínio profissional e o descrédito quanto à condição de enfermo. Conclui-se que a incapacidade se manifesta precocemente na percepção de ineficiência do trabalhador no processo produtivo, porém sua legitimação parece ser tardia, custando o preço da cronificação e da invalidez para o trabalhador.

Palavras-chave: Experiência de enfermidade. Incapacidade. Ler/Dort. Doenças profissionais.

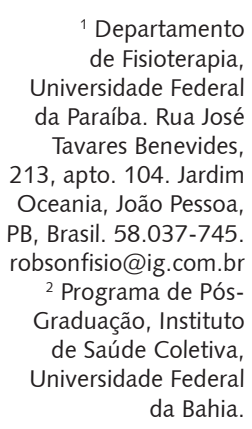

(อ) Interface comunicação SAúde EdUCAÇÃo 


\section{Introdução}

No mundo globalizado e capitalista o imaginário sobre a incapacidade para o trabalho é emblemático e, por vezes, estigmatizante. O estado de invalidez tem em seu bojo uma série de significados com representações mais amplas para a sociedade e seus membros. As Lesões por Esforços Repetitivos/Distúrbios Osteomusculares Relacionados ao Trabalho (Ler/Dort) ${ }^{3}$ parecem personificar bem o ideário de incapacidade, na medida em que se apresentam como uma síndrome complexa, multifatorial e de grande magnitude.

Vários fatores configuram as Ler/Dort como um grande problema socioeconômico e de saúde pública da atualidade no Brasil: a magnitude da prevalência da população acometida, a ampla abrangência de setores da economia impactados, a complexidade clínica que resulta no alto custo da terapêutica, ou mesmo os frequentes afastamentos do trabalho por incapacidade temporária ou permanente.

No ano de 2005, cerca de 492 mil acidentes de trabalho foram registrados no INSS. Comparado com o ano anterior, o número de acidentes de trabalho registrados aumentou 5,6\% . A assistência médica simples cresceu 16,7\%, a incapacidade temporária aumentou $2,8 \%$ e a incapacidade permanente subiu $5,4 \%$. Dentre as doenças do trabalho, as mais incidentes foram sinovite, tenossinovite, lesões no ombro e dorsalgia - enfermidades comumente relacionadas com Ler/Dort (Brasil, 2005).

Pelo prisma do trabalho e das instituições biomédicas que lidam com trabalhadores adoecidos, a incapacidade laborativa no Brasil é cotidianamente referida como deficiência e limitação, mas, sobretudo é comumente chamada de invalidez, termo que é aplicado a todo aquele que é considerado incapaz e insusceptível de reabilitação para o exercício de atividade que lhe garanta a subsistência (Assunção, Almeida, 2003).

Magalhães (1998) já apontava para o grande hiato existente entre a experiência do trabalhador doente e o que é descrito nos manuais técnicos e acadêmicos sobre a incapacidade provocada pela Ler/Dort. Em uma recente revisão, Minayo-Gomez e Thedim-Costa (2003) trataram de questões pertinentes ao adoecimento de trabalhadores e abordaram a práxis social dos trabalhadores, o sentido que conferem ao cotidiano do trabalho, suas formas de ser, sentir, perceber e agir, além de destacarem o trabalhador como sujeito que, ao interagir com as condições objetivas, elabora categorias próprias de pensamento e ação, o que nos remete a novos olhares sobre o tema.

Merlo et al. (2003) estudaram o sofrimento psíquico dos portadores de Ler e afirmaram que existe uma complexa relação que vincula a dor às vivências subjetivas e à identidade social do trabalhador doente. Os autores fazem uma conclusão que parece bastante útil para o presente estudo: "Pensar os efeitos das Ler/Dort na saúde dos trabalhadores implica pensar no lugar atribuído ao trabalho em nossa sociedade, a importância que este assume na produção da subjetividade e também nos modos de adoecer dos trabalhadores" (Merlo et al., 2003, p.134).

Portanto, parece claro que racionalidade biomédica pura não dá conta de explicar toda a complexidade que circunda a incapacidade laborativa (Rocha, 1989). No campo da saúde do trabalhador, já se reconhece a necessidade de se investir no conhecimento da subjetividade do trabalhador e das suas relações de trabalho, pois a mediação da linguagem é considerada essencial para apreender os significados que ele dá a sua vivência e para apreender a dinâmica dos processos mórbidos pela confrontação do sujeito com a realidade do trabalho (Dejours, Abdoucheli, Jayet, 1994).

\footnotetext{
${ }^{3}$ No Brasil, Ler/Dort

foram definidas, pelo Ministério da Saúde, como "afecções que podem acometer tendões, sinóvia, músculos, nervos, fáscia, ligamentos, isolada ou associadamente, com ou sem a degeneração dos tecidos, atingindo principalmente, porém não somente, os membros superiores, região escapular e pescoço" (Lima et al. 2002, p.171).
} 
Parece razoável, então, lançar mão de outras compreensões para tentar traduzir o fenômeno da incapacidade entre trabalhadores com diagnóstico de Ler/Dort, a fim de tornar clara a trajetória de adoecimento desses sujeitos. O entendimento dessas dimensões pode trazer luz para os processos diagnósticos, terapêuticos e de reabilitação desses doentes.

Neste estudo objetivou-se conhecer a experiência de adoecimento de trabalhadores com diagnóstico de Ler/Dort. E o foco centrou-se nos enredos em torno da produção de significados sobre a incapacidade, desde a sua mais incipiente percepção até o processo de reconhecimento social da condição de doente.

\section{Estratégia teórico-metodológica}

Trata-se de um estudo que se apoiou nas noções de "experiência da enfermidade" e nas suas narrativas para dar sentido ao adoecer por Ler/Dort. Entendendo que o corpo não é só um objeto físico ou fisiológico, mas é também uma parte essencial do "eu", e que não está dissociado da consciência, da subjetividade e do mundo vivido (Good, 1994a).

Rejeitando o reducionismo do entendimento da doença restrito ao corpo físico e fisiológico, autores como Huhn (1995), Good (1994b), Kleinman (1988), Young (1982) e Mechanic (1961) entendem a illness como percepções e experiência da pessoa acerca de certos estados socialmente desvalorizados, incluindo a doença, mas não limitado a ela.

Kleinman (1988) esclarece que as expectativas convencionais sobre a illness são alteradas por meio de negociações em diferentes situações sociais, em redes particulares de relações e, por fim, também diferem devido as nossas biografias individuais singulares, o que leva a crer que a experiência da illness é também distintiva ou individual. Amparados nesses pressupostos, Alves e Rabelo (1999, p.171) compreendem a experiência da enfermidade como "a forma pela qual os indivíduos situam-se perante ou assumem a situação de doença, conferindo-lhe significados e desenvolvendo modos rotineiros de lidar com a situação".

Esses autores falam do "sentir-se mal" como uma referência à corporeidade, contudo não se referindo unicamente a alterações ou disfunções orgânicas, mas também ao corpo vivido, indissociável da subjetividade. Com isso não se quer afirmar que a enfermidade se constrói apenas com base em atitudes reflexivas destacada do fluxo de vivências. Mais que isso, ela também se substancia como significados por meio da construção intersubjetiva, isto é, a partir de processos comunicativos de definição e interpretação reconhecidos e legitimados socialmente (Alves, Rabelo, 1999).

O conceito de experiência da enfermidade se estabelece como categoria analítica, e serviu de eixo para orientar o tratamento do material coletado, no intuito de capturar um sentido compartilhado entre o plano teórico e o empírico, o que parece bastante apropriado para o contexto da Ler/Dort e da incapacidade, visto que a perturbação provocada pela incapacidade assimila o curso da história de vida dos trabalhadores acometidos.

Questiona-se: como é dada, ao indivíduo, a capacidade de expressar, interpretar e comunicar a sua experiência de sofrimento? Respondendo a esse questionamento, as narrativas de enfermidade podem desempenhar um papel central nos casos de incapacidade devido à Ler/Dort, uma vez que elas têm a propriedade de organizar uma experiência e fazer com que esta tenha sentido (Helman, 2003).

Good (1994a) acredita que as narrativas ou histórias com enredos são uma das tentativas de dirimir a dissolução do mundo da vida e uma forma também utilizada pelos sofredores e pela sociedade para reconstruir o mundo desestruturado pela doença. $\mathrm{O}$ enredo, entendido aqui como aquilo que dá ordem a uma história, representa mais do que uma estrutura de relações sequenciais: o enredo é criado pelos leitores momento a momento, na tentativa de extrair a estrutura e o significado dos eventos.

Com isso, entende-se que a incapacidade comporta componentes subjetivos originados no ato individual de perceber o sentido do mal-estar, mas também se adensa e se completa nos processos intersubjetivos adquiridos na vida cotidiana, onde a doença é legitimada e objetivada. Portanto, é dessa dialética que nascerão os primeiros rudimentos de uma compreensão dos significados da incapacidade. 
A heterogeneidade de características pessoais e profissionais dos trabalhadores e a saturação das informações foram critérios importantes para a seleção e determinação do número final de sujeitos desta pesquisa. O estudo contou com oito trabalhadores com diagnóstico de Ler/Dort há mais de um ano, sob regime de beneficio da Previdência Social do Brasil por "auxílio-doença" ${ }^{4}$ ou "aposentadoria por invalidez" ${ }^{5}$. Esses diagnósticos foram dados após criteriosa investigação clínica e laborativa, com o estabelecimento do nexo feito pelos peritos do CESAT (Centro de Estudo de Saúde do Trabalhador), órgão público do estado da Bahia, com notória experiência em doenças ocupacionais e vigilância em saúde do trabalhador. Os informantes são de ambos os sexos, pertencentes a classes sociais e inserções religiosas diferentes, com variados níveis de gravidade da lesão e causas do adoecimento, pertencentes a regimes diferenciados de trabalho: operários da indústria, comércio e do setor de serviços.

A produção dos dados foi realizada no período de julho a outubro de 2005. Os instrumentos adotados foram o roteiro de entrevista e o diário de campo. Neste último foram registrados: as interpelações, pedidos de observação e exame de anomalias presentes no corpo dos trabalhadores entrevistados, solicitações de apreciação de exames de imagem e relatórios de especialistas. Todos esses eventos ocorridos no transcurso das entrevistas.

Durante as entrevistas, com base no seguinte tópico central: "Destaque as repercussões provocadas pela doença, contando detalhadamente quando e como você começou a trabalhar e como essa doença entrou na sua vida", vários temas foram explorados, desde a inserção do entrevistado no mundo do trabalho, passando pela história da percepção inicial do adoecimento, caminhos trilhados para o tratamento e o reconhecimento social da doença.

Corin et al. $(1993,1990)$ apud Rabelo (1999) afirmam que a coleta de narrativas sobre a doença possui nítidas vantagens sobre outras técnicas, pois o saber médico não profissional está embutido em contextos de ação e as narrativas permitem que se mantenha este elo fundamental entre saber e contexto.

Escolheu-se a entrevista narrativa, pois, dentre os modelos de entrevista em profundidade existentes, é o que busca reconstruir acontecimentos sociais com base na história narrada dos sujeitos; além disso, permite ao entrevistado relembrar o que aconteceu, fornece uma sequência para sua experiência, ajuda a encontrar explicações para os fatos e eventos e, por fim, modela os acontecimentos que compõem a vida individual e social, atribuindo sentido às experiências (Jovchelovitch, Bauer, 2002).

Emergiram, do trabalho de campo, sentidos compartilhados sobre a experiência da incapacidade, que circularam em torno do sentir-se normal, da ineficiência do corpo, dos signos do corpo e do nome para a incapacidade. Essas categorias agregaram conteúdos úteis para se apreender melhor a produção de significados que o adoecimento relacionado a Ler/Dort traz no bojo de seu curso enunciado pelas narrativas de construção da incapacidade no trabalho e no cotidiano dos trabalhadores entrevistados.

O material empírico obtido da entrevista narrativa foi analisado sob a ótica da análise temática, considerada pertinente para a presente pesquisa, visto que constitui uma interpretação das entrevistas, juntando estruturas de relevância dos sujeitos da pesquisa com as do entrevistador (Jovchelovitch, Bauer, 2002).

Foram adotados os procedimentos éticos conforme a Resolução n. ${ }^{\circ}$ 196/96 do Conselho Nacional de Saúde e suas complementares e, a fim de preservar a identidade dos participantes do estudo, foram utilizados nomes fictícios no corpo deste texto.
${ }^{4}$ Ver artigos 71 e 80 do Decreto $n^{\circ} 3.048 / 99$ do Regulamento da Previdência Social. ${ }^{5}$ Ver artigos 43 a 50 do Decreto $n^{\circ} 3.048 / 99$ do Regulamento da Previdência Social. 


\section{Resultados e discussão}

\section{O sentir-se normal}

Good (1994a), ao tratar das representações da experiência do adoecimento dos que sofrem por dor crônica, chama atenção para que se focalize como as dimensões do mundo percebido são desestruturadas, dilaceradas, interrompidas, como resultado de uma enfermidade séria. Essa orientação torna-se útil no presente estudo, visto que a experiência de normalidade precede a vivência de incapacidade, tanto para o trabalho quanto para a vida.

Para Donnangelo (1979, p.23), "A condição de normalidade constrói-se no desenrolar da própria vida, a qual é, em si, normativa, capaz de instituir normas e modificar as normas que institui.". Com isso, para averiguar o que é normal ou patológico para o corpo, é necessário olhar para além do próprio corpo na perspectiva anatomofisiológica. É percebê-lo também como dotado de um conjunto de ações, habilidades e competências que retratam sua instrumentalidade disposta na sociedade para agir no cotidiano, sobretudo como agente do trabalho.

Os informantes desta pesquisa destacam como elementos visíveis de suas atuações no mundo do trabalho e da vida: eficiência, agilidade, precisão, capacidade de liderança, versatilidade, experiência acumulada, dedicação, interesse de crescimento, disponibilidade, disposição incessante, equilíbrio emocional, dentre outros. Todos esses adjetivos traduzem-se no fazer e no agir, que operam na dimensionalidade da participação e do engajamento na vida social:

[...] eu trabalhava com a supervisão das linhas de rede; era toda sobre minha responsabilidade, eu tinha que estar dando, era assim tipo uma monitoria, tá? Já pagou? Não pagou? Se não pagou, eu tenho que entrar em contato com o cliente, então, era pra mais de, vamos dizer, na época era pra mais de duzentas linhas de rede [...] ah, eu tinha uma vida social assim maravilhosa, graças a Deus! Eu tive um casamento maravilhoso de 18 anos de casada, ta entendendo? E com quatro filhos, né? E eu tinha vida muito sossegada, muito equilibrada financeiramente, certo? (Mara- secretária)

Mas, subjazem também outros sentidos compartilhados como próprios da dimensão do trabalho e da vida, como: companheirismo, solidariedade, validação da competência, responsabilidade, honestidade, ética profissional, competição, integridade física e fascínio por sentir-se útil - adjetivos que, em última análise, parecem conferir a noção de moral para esses trabalhadores:

Minha mãe não trabalhava e meus outros irmãos todos eram de menor e não trabalhavam, então, quando eu trabalhei no banco foi um momento que melhorou bastante a situação da gente, financeira, entendeu? Então, meu salário era muito importante naquele momento, aí eu tinha medo. Eu pensava: "poxa, se eu for demitida, como é que vai ser lá em casa? (Margareth - digitadora)

[...] E no dia que eu não ia, quando a chuva estava de mais que eu não ia. Era como se tivesse uma cobrança dentro de mim. Eu não tinha tido responsabilidade. Lá não ia coordenadora, não ia ninguém. Eu nunca gostei de falhar. Só se fosse um caso de muita necessidade. (Mathildes cabeleireira)

Com isso, não se deseja propor a existência de um "ethos" que norteia o mundo da vida desses trabalhadores, mas sim, criar uma base inicial de entendimento sobre suas concepções de vida e trabalho. Não se pretende também fazer um estudo mais aprofundado dos construtos de normalidade e de moralidade, mas sim, trazer à tona proposições como a de Helman (2003, p.130) quando afirma que "[...] as narrativas emergem em momentos de ruptura inesperada no fluxo da vida diária. Isso implica o conceito de um estado prévio de normalidade, que, por sua vez, pode ser amplamente definido em termos culturais". 
Portanto, a falha moral apresenta-se como uma quebra na possibilidade de continuar reproduzindo símbolos sociais tão caros à existência humana em coletividades como: responsabilidade, capacidade de competição, manutenção da subsistência, dentre outros já citados acima. Esses achados refletem a ideia de que, nas sociedades capitalistas, o corpo adquire significado na estrutura histórica da produção, expresso no modo como são utilizados e nos padrões de ação física e cultural a que deverão ajustar-se. Tomando como base esse complexo de ações, funções, competências e habilidades na relação que o corpo faz com o mundo da vida e do trabalho, torna-se claro que o estado de normalidade do corpo depende não só da estrutura anatômica e fisiológica, mas também das qualificações e determinações que adquire no plano da existência material e social (Donnangelo, 1979).

\section{A ineficiência do corpo para o trabalho}

A percepção de que alguma coisa não está bem para os trabalhadores entrevistados passa pela dimensão do corpo que serve ao trabalho, na expressão do descompasso entre a produção exigida pelo trabalho e a produzida pelo corpo do trabalhador, evidenciadas pela diminuição da produção, das constantes advertências dos superiores hierárquicos, da detecção da queda do rendimento nos processos de avaliação da empresa e a perceptível diminuição da agilidade para o trabalho. Esses desarranjos são percebidos pelos indivíduos, porém não se traduzem inicialmente como doença ou como incapacidade:

[...] eu via todo mundo dando produção e eu não conseguia chegar, né? Eu fazia somente as coisas pela metade, eu comecei a fazer as coisas pela metade e isso já estava me incomodando. E lá na empresa eles têm um processo de avaliar de seis em seis meses e minhas avaliações estavam começando a cair, tá entendendo? E isso começou a me chamar a atenção [...]. (Margareth - digitadora)

A inquietação por não poder atender aos anseios da produção no trabalho também contribui para os primeiros indícios de uma identidade de incapacidade, precocemente marcada pelas incertezas quanto ao desempenho funcional no trabalho e pelo sofrimento psicológico gerado. Essas insatisfações se manifestam por meio da autoavaliação do próprio rendimento e da qualidade do trabalho:

"Eu não conseguia produzir, aquilo estava me matando, tá entendendo? E aí eu comecei a tomar antidepressivo, fui pra psiquiatra pensando que eu estava com problema na cabeça [...]" (Mara secretária).

Sobre os relatos acima, Good (1994a) argumenta que as categorias propostas por Schutz, para a análise da 'realidade do senso comum', podem ser bastante eficazes para se entender essas percepções iniciais como uma desestruturação do mundo da vida diária, onde o trabalho é parte integrante. Dentre essas categorias, duas proposições parecem delinear satisfatoriamente os achados empíricos. A primeira está pautada no princípio de que "No dia a dia, o 'eu' é tido como autor das ações, portanto, total e não dividido" (Good, 1994a, p.124). Ou seja, nós agimos no mundo por intermédio dos nossos corpos, e nossos corpos são sujeitos de nossa ação. Nas falas, acima, percebemos os trabalhadores estranhando seus corpos, diferenciando-os do "eu" que estava agindo e vivenciando.

A segunda proposição está baseada na ideia de tempo, ou seja, numa perspectiva de tempo que o sofredor compartilha com as outras pessoas. O descompasso apresentado pelos trabalhadores e seus anseios não correspondidos de produção denunciam uma diacronia entre o tempo interior e o tempo exterior. Como corolário, afirma Good (1994a, p.126): "O mundo privado não apenas perde sua relação com o mundo em que as pessoas vivem, mas também a sua própria dimensão organizadora começa a se desestruturar". Os reflexos desses eventos estão para além do mundo do trabalho, pois se pronunciam também nas atividades da vida diária.

Para Good (1994a, p.131), "A experiência vivida é organizada em um ritmo social natural, que se move da atividade para o repouso, do trabalho para o lazer, da concentração para o relaxamento. A dificuldade em se envolver em um ou outro desses aspectos é sinal de patologia, ou uma falha moral". A desestruturação do mundo da vida mediada pela falha moral dá lugar a um imaginário de incapacidade, 
${ }^{6}$ Expressão extraída do texto de Ferreira (1994). que ganha força nas constatações das limitações para a realização das atividades da vida diária - como atividades domésticas, lazer, atividade esportiva - e na ideia da deformidade progressiva das estruturas do corpo que vai se instalando. Com isso o ritmo normal da vida vai se quebrando, pois o homem vai se submetendo, aos poucos, aos ritmos vitais do seu corpo que adoece:

É horrível o psicológico. Na verdade eu me sentia inútil, porque eu não podia mais fazer nada dentro de casa. Eu sempre fui ativa, sempre! Eu nunca fiquei parada, dentro de casa eu não fico parada. Então, eu me via assim numa situação que eu tinha que ficar quieta num canto, eu não podia ler porque o movimento de passar a página me incomodava. (Margareth - digitadora)

\section{O corpo "suporte de signos"6}

Concordando com o trabalho de Magalhães (1998), o presente estudo mostrou que mudanças no comportamento, nas atitudes e nas estruturas do corpo ajudam a consolidar o imaginário de incapacidade por meio: da reclusão, da tristeza, da ideia fixa na possibilidade de ficar inútil, na perda de confiança no corpo, no nervosismo que subitamente toma o ser, na maneira como vê o seu corpo físico e o coloca no mundo, e nas mudanças de hábitos e práticas próprios da vida cotidiana. Estes parecem condensar-se na fala destas trabalhadoras:

Eu tinha vergonha de meu corpo, eu tinha vergonha de usar blusas decotadas, né? Meus braços eram monstruosamente cheios de nódulos, né? Aqui, essa parte do braço eram cheios de nódulos; isso daqui meu eram horrorosos, meus dedos eram horrorosos, tudo em mim era feio, né? (Mara - secretária)

[...] primeiro eu comecei a sentir esse negocio aqui esticando [região do bíceps do braço], esticando mesmo parecendo que minha veia tava esticando, ai eu disse a Chica, oh Chica eu não aguento mais. Chica também tem esse problema tanto que ela é com essa mão dela, ela mexia mais com essa mão, então até quando indo lá desligar a máquina ela suspendia o corpo todo assim pra desligar porque ela já não levantava, aí até hoje ela tá trabalhando, não sei como [...]. (Maura operadora de corte e solda)

Em certa medida, foi angustiante perceber que, no momento das entrevistas, os informantes ao se referirem às marcas das possíveis lesões, modificações de contornos nas estruturas dos seus corpos, na presença de nodulações dolorosas, no rubor da pele e na temperatura desigual dos segmentos corporais, solicitavam insistentemente, do entrevistador, a atenção total à localização exata, o esforço imaginativo do que havia se sucedido na sua anatomia e fisiologia, mesmo que não houvesse mais indícios de que algo acontecera ali; e, muitas vezes, requeriam a palpação solícita das estruturas corporais acometidas ou em processo de acometimento.

Para Merleau-Ponty (1999), os estados e sensações corporais experimentadas pelos indivíduos e as interpretações feitas fazem parte de códigos e de grupos sociais específicos. Nessa perspectiva, o corpo pode ser entendido como "suporte de signos". Leach (1976) apud Ferreira (1994, p.102) indica que "a função do signo é comunicar ideias por intermédio de mensagens, ou 
seja, o signo tem o objetivo de transmitir uma informação, fazendo parte assim de um processo de comunicação". Tomando como base essa ideia do corpo como signo, para pensar a formulação da incapacidade, pode-se supor que, por intermédio das mensagens emitidas pelo corpo na forma das experiências da enfermidade e dos sinais objetivos advindos das estruturas, sistemas e funções corporais, chegar-se-á a um significado: a incapacidade.

Essa formulação encontra bases sólidas na fenomenologia da percepção trabalhada por MerleauPonty (1999), na medida em que tenta entender o mundo experiencial do sofredor por meio da tomada de consciência a partir da experiência corporificada em todas as suas modalidades sensoriais. Com base nesses princípios, a compreensão da incapacidade não depende unicamente da moldagem cognitiva da experiência, mas também da apreensão de informações do corpo sensorial.

Kleinman (1988) adensa a discussão acima trazendo, para dentro do domínio da enfermidade, a experiência dos processos de monitoramento corporal. Isso fica patente nos acometidos por Ler/Dort, por meio das mudanças anatômicas e fisiológicas do corpo, caracterizadas por inchaços, nodulações, diminuição da amplitude do movimento articular, déficit de sensibilidade e força, bem como alterações do estado de humor e outras funções cognitivas experimentadas por esses sujeitos.

Esses sinais, quando percebidos, categorizados e analisados pelas lentes do senso comum, numa linguagem acessível a todas as pessoas ligadas ao grupo social do trabalhador acometido, traduzemse em formas de angústia causadas pelo processo de adoecimento. Assim, pode-se concluir que as percepções embrionárias de incapacidade se dotarão de significado na medida em que se estabeleçam e sejam visíveis e palpáveis para os indivíduos e para os membros da sociedade.

\section{O nome para a incapacidade}

Metáforas como: "você se sente um lixo, um nada!", "ah, você está é de lerdeza", "você sente inútil", comumente aparecem nos relatos de experiência dos trabalhadores em processo de adoecimento, como forma de comunicar a experiência da enfermidade adotada pelos narradores dessas histórias. No entanto, se faz necessário retomar a conceituação e a crítica à definição clássica de metáfora para que se entendam as proposições acima como metáforas da incapacidade.

Aristóteles (1457), apud Sontag (1989), diz, em sua Poética, que a metáfora 'consiste em dar a uma coisa o nome de outra'. Porém, muitos teóricos da literatura e filósofos têm criticado a proposição de que ao se reduzir a metáfora a uma mera substituição de palavras não se dá conta da dimensão de sentido potencial dela. Com base nessa afirmação, Ricoeur (1987) apud Alves, Rabelo (1999, p.177) compreende que o lugar específico da metáfora é a frase, e não a palavra, uma vez que "as metáforas dizem respeito à função de predicação da frase: operam, inicialmente, instituindo uma tensão, no seio do enunciado, entre duas interpretações opostas; é o conflito entre ambas que sustenta a metáfora".

É com base nesse rompimento criativo com o uso comum da linguagem metafórica que se permite apostar em outros sentidos fora daqueles amarrados pela interpretação literal e se obtém uma nova informação oriunda de estruturas internas do enunciado. Partindo desse pressuposto, algumas falas que deram origem às metáforas de incapacidade, acima, serão retomadas em seus contextos a fim de atribuir-Ihes sentido:

[...] você se sente um lixo, um nada! Sabe? Porque você está dizendo pra pessoa que você está sentindo dor, que você não está aguentando, e a pessoa diz assim: "não, mas você fisicamente, você não tem nada", porque você não tem um defeito, entendeu? Você tem as mãos, os braços, tudo, então ele acha que você não tem nada. (Margareth - digitadora)

[...] naquela época a gente até brincava com isso, né? Hoje eu não brinco (ri). O pessoal falava 'ah, to de LER' e não sei o quê, e a gente: 'ah, você está é de LERdesa' [...] porque era uma dorzinha assim que você até ligava até a alguma coisa. (Matheus - bancário)

São representações embutidas nas metáforas, empregadas pelos trabalhadores, nesta pesquisa, para dar sentido ao seu sofrimento: o sentimento de desvalorização integral do ser, a percepção do 
desperdício dos anos de vida por conta do adoecimento, a discriminação e rejeição para o mundo do trabalho, a sensação de não mais ser reconhecido dentro do seu próprio ambiente de trabalho, o atestado público de declínio profissional, o descrédito quanto à condição de enfermo, e o desengano quanto à possibilidade de melhora.

Sontag $(2002,1989)$, em suas publicações, explora os sentidos compartilhados das metáforas relacionadas à tuberculose, ao câncer e à aids, mostrando que a falta de conhecimento mais aprofundado sobre a tuberculose, no passado, e sobre o câncer e a aids, atualmente, tornam o contexto em torno dessas moléstias obscuro, o que tende a sobrecarregá-las de significação. Essa constatação é particularmente compatível com a incapacidade por Ler/Dort, pois sendo enfermidade que se acredita ter múltiplas causas, reúne as maiores possibilidades de ser usada como metáfora para o que se considera social ou moralmente deturpado.

As metáforas referentes às enfermidades não são enunciados estanques que se perpetuam ao longo dos anos, elas podem se modificar na medida do grau de compreensão do adoecimento e, também, na proporção da evolução da cura. Assim, o mais importante é compreender o uso das metáforas nos momentos em que elas se estabelecem. Nesse sentido, as metáforas da incapacidade por Ler/Dort parecem revelar, como significados: a insuficiência do sistema biomédico em produzir modelos explicativos coerentes com intervenções eficazes e a falha da sociedade capitalista em construir um modelo industrial avançado que regule a produção adequadamente. Portanto, existe um potencial revelador sobre o qual Alves e Rabelo chamam atenção ao dizer que:

Nas narrativas de aflição, as metáforas desempenham um papel central: constituem estratégia de inovação semântica, que estendem sentidos habituais para domínios inesperados, oferecendo assim uma ponte entre a singularidade da experiência e a objetividade da linguagem, das instituições e dos modelos legitimados socialmente. (Alves, Rabelo, 1999, p.173)

As narrativas de enfermidade não são povoadas unicamente pelas metaforizações, as substantivações também aparecem nesses discursos, inicialmente, como significado cultural particularmente poderoso, frequentemente de um tipo estigmatizador e, posteriormente, vão se dotando de valores legitimadores reconhecidos pela sociedade sob a identidade de inútil, incapaz ou inválido: "Quando [meu sobrinho] viu como era minha aposentadoria por invalidez ele disse: 'minha tia, se você for se meter a querer voltar, vai ser uma complicação tão grande que não aconselho de jeito nenhum" (Martha - bancária).

A atribuição de um nome a uma enfermidade é largamente explorada pela literatura, e autores como Kleinman (1988) e Good (1994a) reconhecem o caráter muitas vezes estigmatizador do nome atribuído às enfermidades, mas colocam essa nomeação como um divisor de águas, pois a doença que era um domínio perceptual da mente do sofredor agora ganha uma outra dimensão. Nesse sentido, dar um nome para a origem do sofrimento é conseguir poder para aliviá-lo, é também um passo importante para a reestruturação do mundo da vida, mais ainda, confere poder para tornar o "eu" integrado no contexto mais amplo do sofrimento (Good, 1994a).

Kleinman (1988) defende o fato de que a ação de nomear uma enfermidade é realizada pela pessoa doente e pelo seu círculo com o objetivo de superar uma determinada ocorrência considerada normal ou desestruturante, como é o caso da incapacidade em Ler/Dort. Para isso, o sofredor e as pessoas do seu meio social transformam a experiência da enfermidade em algo domesticado e controlado, ou seja, em uma experiência cultural. Dessa forma, o nome atribuído confere uma teia de possibilidades: dá um caráter de veracidade e legitimação ao evento, credencia para outras ações terapêuticas, abre canais de entendimento sobre a doença e outros aspectos relacionados a ela, possibilita a tomada de decisões e a luta por direitos.

Good (1994, p.131) sintetiza bem esses achados ao afirmar que "similarmente, o nomeamento simbólico das fontes do sofrimento servem para formular o objeto do tratamento e, portanto organizar uma série de respostas sociais e de atividades terapêuticas".

As narrativas sobre a incapacidade parecem cumprir um importante papel na medida em que evidenciam a força no sentido negativo e pejorativo contida nas metáforas, na conotação que ganham 
no mundo do trabalho, bem como a capacidade de (re)significação que o adoecimento adquire em face da nomeação legitimadora para um infortúnio estranho e estigmatizador que é a Ler/Dort.

\section{Considerações finais}

Então, incapaz por quê? Inválido para quê? O enredo apresentado neste artigo mostra que é, na dinâmica do dia-a-dia e do trabalho, que se percebem os primeiros indícios de instalação da incapacidade em Ler/Dort; e que o imaginário de invalidez traz com ele o reconhecimento de que o mundo da vida está se desestruturando, e isso é revestido por situações de sofrimento em vários planos da vida.

A narrativa de experiência e as metáforas de incapacidade podem funcionar como recursos importantes para o reconhecimento inicial dos sentidos da incapacidade e dos seus significantes. Kleinman (1988) afirma que avaliar o sofrimento requer mais do que simplesmente adicionar algumas questões a um formulário de autorrelato ou a uma entrevista padronizada. A avaliação do sofrimento requer informação diferente e válida das narrativas da experiência do adoecimento. Nesse sentido, a etnografia, a biografia, a história e a psicoterapia são métodos de pesquisa apropriados para criar conhecimento sobre o mundo pessoal do sofrimento. Esses métodos nos permitem captar, por trás dos simples sons da dor corporal e sintomas psiquiátricos, a linguagem interior complexa da dor moral, do desespero e do sofrimento.

A atenção à saúde dos trabalhadores tidos como inválidos para o trabalho precisa ser revista por meio de uma lente mais ampliada, uma perspectiva holística de cuidado, de modo que se atente para a necessidade de restabelecimento do mundo da vida dos sujeitos utilizando-se de manejos mais positivos, ou seja, intervenções com bases dialógicas e que primam pela valorização da fala dos sujeitos acometidos por Ler/Dort.

Essas reflexões parecem bastante pertinentes para o campo da saúde do trabalhador, visto que depositam sobre a questão da experiência da incapacidade outras bases de entendimento, que podem ser úteis para o processo que vai da prevenção do adoecimento à reabilitação do trabalhador doente, e lançam, nessa discussão, a necessidade de se refletir de forma mais profunda sobre os questionamentos feitos anteriormente.

\section{Colaboradores}

Os autores trabalharam juntos em todas as etapas de produção do manuscrito.

\section{Referências}

ALVES, P.C.B.; RABELO, M.C.M. Significação e metáfora na experiência da enfermidade. In: RABELO, M.C.M.; ALVES, P.C.B.; SOUZA, I.M.A (Orgs.). Experiência da doença e narrativa. Rio de Janeiro: Fiocruz, 1999. p.171-86.

ASSUNÇÃO, A.A.; ALMEIDA, I.M. Doenças osteomusculares relacionadas com o trabalho: membro superior e pescoço. In: MENDES, R. (Org.). Patologia do trabalho. São Paulo: Atheneu, 2003. p.1501-39.

BRASIL. Ministério da Saúde. Secretaria de Políticas de Saúde. Protocolo de investigação, diagnóstico, tratamento e prevenção das lesões por esforços repetitivos. Brasília: MS, 2000. 
BRASIL. Ministério da Previdência Social. Anuário Estatístico da Previdência Social 2005 - AEPS. Seção IV - Acidentes do Trabalho. Disponível em: < http://www.mpas.gov.br/ aeps2005/14_01_03_01.asp>. Acesso em: 25 jun. 2007.

DEJOURS, C.; ABDOUCHELI, E.; JAYET, C. Psicodinâmica do trabalho: contribuições da escola Dejouriana à análise das relações prazer, sofrimento e trabalho. São Paulo: Atlas, 1994.

DONNANGELO, M.C.F.; PEREIRA, L. Saúde e sociedade. São Paulo: Duas Cidades, 1979.

FERREIRA, J. O corpo sígnico. In: ALVES, P.C.B.; MINAYO, M.C.S. (Orgs.). Saúde e doença: um olhar antropológico. Rio de Janeiro: Fiocruz, 1994. p.101-12.

GOOD, B.J. The body, illness experience, and the lifeworld: a phenomenological account of chronic pain. In:_. Medicine, rationality, and experience: an anthropological perspective. Cambridge: Cambridge University Press, 1994a. p.116-34.

. Illness representations in medical anthropology: a reading of the field. In: Medicine, rationality, and experience: an anthropological perspective. Cambridge: Cambridge University Press, 1994b. p.25-63.

HUHN, R.A. Sickness and healing: an anthropological perspective. New Haven: Yale University Press, 1995. p.327.

HELMAN, C.G. Interações médico-paciente. In: . Cultura, saúde e doença. Porto Alegre: Artmed, 2003. p.109-45.

JOVCHELOVITCH, S.; BAUER, M.W. Entrevista narrativa. In: BAUER, M.W.; GASKELL, G. (Orgs.). Pesquisa qualitativa com texto, imagem e som: um manual prático. Petrópolis: Vozes, 2002. p.90-113.

KLEINMAN, A. The illness narrative: suffering, healing and the human condition. New York: Basic Book, 1988.

LIMA, M.A.G.; FERNANDES, R.C. Lesões por Esforços Repetitivos/Distúrbios Osteomusculares Relacionados com o Trabalho - LER/DORT. In: BAHIA. Secretaria da Saúde do Estado. Superintendência de Vigilância e Proteção da Saúde. Centro de Estudo da Saúde do Trabalhador/ SESAB/SUVISA/CESAT. Manual de normas e procedimentos técnicos para vigilância da Saúde do Trabalhador. Salvador: CESAT/SESAB, 2002. p.171.

MAGALHÃES, L.V. A dor da gente: representações sociais sobre as lesões por esforços repetitivos. 1998. Tese (Doutorado) - Faculdade de Ciências Médicas, Universidade Estadual de Campinas, Campinas. 1998.

MECHANIC, D. The concept of illness Behavior. J. Chronic Dis., v.15, p.189-94, 1961. MERLEAU-PONTY, M. Fenomenologia da percepção. São Paulo: Martins Fontes, 1999.

MERLO, A.R.C. et al. O trabalho entre prazer, sofrimento e adoecimento: a realidade dos portadores de lesões por esforços repetitivos. Psicol. Soc., v.15, n.1, p.177-236, 2003.

MINAYO-GOMEZ, C.; THEDIM-COSTA, S.M.F. Incorporação das ciências sociais na produção de conhecimento sobre trabalho e saúde. Cienc. Saude Colet., v.8, n.1, p.125-36, 2003.

RABELO, M.C.M. Narrando a doença mental no Nordeste de Amaralina: relatos como realizações práticas. In: RABELO, M.C.M.; ALVES P.C.B.; SOUZA I.M.A. (Orgs.).

Experiência da doença e narrativa. Rio de Janeiro: Fiocruz, 1999. p.75-89.

ROCHA, L.E. Tenossinovite como doença do trabalho no Brasil: a atuação dos trabalhadores. 1989. Dissertação (Mestrado) - Departamento de Medicina Preventiva, Faculdade de Medicina, Universidade de São Paulo, São Paulo. 1989.

SONTAG, S. A doença como metáfora. Rio de Janeiro: Graal, 2002.

Aids e suas metáforas. São Paulo: Companhia das Letras, 1989.

YOUNG, A. The anthropologies of illness and sickness. Ann. Rev. Anthropol., v.11, p.257-85, 1982. 
NEVES, R.F.; NUNES, M.O. Incapacidad, cotidiano y subjetividad: la narrativa de trabajadores con LER/DORT. Interface - Comunic., Saude, Educ., v.13, n.30, p.55-66, jul./set. 2009

Se ha objetivado conocer la experiencia de enfermar en trabajadores con LER/DORT con apoyo en los presupuestos de la "experiencia de enfermedad" y en las "narrativas de la enfermedad. Se utilizaron la técnica de entrevista narrativa y el análisis temático para aprehender las categorías que emergieron del discurso de los ocho sujetos participantes de esta investigación. Los resultados indican que la "ineficiencia del cuerpo" para el trabajo se evidenció por el descompás entre la producción exigida por el trabajo y la producida por el cuerpo del trabajador. El cuerpo funciona como un"soport e de signos" de los cambios en el comportamiento y en las estruoturas del cuerpo ayudando a consolidar lo imaginario de Incapacidad, "Las metáforas" representan el certificado público de declinio profesional y el descrédito en cuanto a la condición de enfermo. Se concluye que la incapacidad se manifiesta precozmente en la percepción de ineficiencia del trabajador en el proceso productivo pero su legitimación parece tardía, costando el precio de cronicidad y de la invalidez para el trabajador.

Palabras clave: Experiencia de enfermedad. Incapacidad. LER/DORT. Enfermedades profesionales.

Recebido em 15/09/2008. Aprovado em 20/02/2009. 